\title{
Les alternances de codi: un recurs comunicatiu
}

\author{
Carles de Rosselló i Peralta
}

Universitat de Barcelona

\begin{abstract}
Resum: Durant temps, l'ús de dues o més llengües en un mateix fragment de parla havia estat considerat com una manca de competència lingüística del parlant. Aportacions com les de Gumperz al principi dels anys vuitanta capgiren aquesta visió $i$ les alternances de codi comencen a percebre's com un recurs comunicatiu més de què disposa el parlant. En aquest article presentem alternances produïdes per infants de P3 no atribuïbles a la manca de competència lingüistica i intentem justificar-ne la interpretació a partir de l'anàlisi del context en què es produeixen.
\end{abstract}

Paraules clau: Alternances de codi, apunts de contextualització, adquisició lingüistica, adquisició de les normes sociopragmàtiques.

Abstract: For some time, the usage of two or more languages in the same speech event was considered a lack of linguistic competence. Gumperz's contributions in the early 80's, among others, have flipped this belief and code switching is starting to be perceived as a communicative resource that a speaker can use. This article presents instances of code switching carried out by children aged 3 to 4 . The article discusses why these episodes are not examples of a lack of linguistic competence by analyzing the context in which they took place.

Keywords: Code switching, contextualization cues, linguistic acquisition, acquisition of sociopragmatic norms.

\section{Introducció}

Dins del camp del contacte de llengües, les alternances de codi són un dels fenòmens que ha captat més l'atenció dels investigadors. Com en altres camps de la ciència, al principi no s'hi atorgava una atenció especial, atès que sovint se les relacionava amb una manca de competència del parlant bilingüe, que usava les dues llengües en un mateix fragment de parla - aquesta seria la definició d'alternança- perquè era incapaç de mantenir una conversa monolingüe. Weinreich, conjuntament amb Haugen, un dels impulsors de l'estudi sistemàtic dels fenòmens de contacte de llengües, defensa una visió de la lingüística en què l'alternança és una "desviació de la norma" monolingüe (1953). Els treballs de Gumperz (1982) i Gumperz (ed.) (1982) influencien decisivament les obres posteriors dedicades a les alternances perquè les encamina cap a la perspectiva social, la qual havia romàs inexplorada fins aleshores. Bàsicament, Gumperz relaciona l'alternança $\mathrm{amb}$ una sèrie de funcions socials que es produeixen amb regularitat. Aquesta via d'estudi possibilita examinar l'alternança de codi com un procés social i interaccional i no com un dèficit pel qual hom pugui ser estigmatitzat.

Naturalment, l'anàlisi de les alternances no es concentra solament a explicar-ne el significat social. Una via molt fructífera d'estudi és la que va iniciar Poplack (1980), centrada a escatir els aspectes lingüístics de l'alternança. La distinció entre alternances intraoracionals -les que es 
produeixen dins de l'oració- i alternances interoracionals - les que es produeixen en els límits de dues oracions- ha conegut una gran difusió entre els especialistes, encara que, per raons d'espai, en aquest article ens limitarem a l'enfocament més social.

De manera que si concentrem la nostra mirada sobre les funcions pragmàtiques de l'alternança, podem distingir-ne dues classes: d'una banda, la tria de llengua $i$, de l'altra, l'alternança conversacional (Köppe i Meisel, 1995). La tria lingüística és l'establiment d'un codi que s'utilitza de manera sistemàtica en el marc d'una interacció i que està relacionat $\mathrm{amb}$ l'interlocutor, amb el tema de la conversa o amb el lloc on es produeix. ${ }^{1} \mathrm{~A}$ Catalunya, se sap bé que el factor determinant de la tria és la persona, més que no pas cap dels altres factors esmentats (Vila, 1996). Per la seva banda, les alternances conversacionals es caracteritzen per ser breus i no impliquen renegociar la llengua establerta com a base de la interacció (Boix-Fuster, 1993). A través de les alternances es vehiculen funcions discursives que Gumperz va resumir en: $a$ ) citació de paraules d'altri; $b$ ) especificació del destinatari; $c$ ) ús d'interjeccions; d) reiteració del missatge per emfasitzar o clarificar; e) qualificació del missatge (es qualifica en una llengua allò que s'acaba de dir en una altra), if) oposició entre personalització i objectificació per marcar apropament o distanciament amb els fets descrits.

Malgrat que l'estudi de les funcions de les alternances va conèixer una certa proliferació, Auer (1995) apunta que simplement detallar les situacions en què es produeix l'alternança resulta inadequat per una sèrie de motius. Aquí en destacarem dos: d'una banda, perquè la confecció de llistes no pot explicar per què les alternances tenen un significat conversacional i, de l'altra, perquè les llistes pressuposen que l'alternança ha de tenir el mateix estatus tant si el canvi es produeix de la llengua a a la llengua b com si el canvi es produeix a la inversa. Tanmateix, això no és així, ja que fins i tot en una mateixa comunitat de parla el significat conversacional dependrà de la direcció de l'alternança. Auer, a més, defensa que

1 Myers-Scotton (1993) reporta que la tria lingüística també pot ser l'alternança de codi constant. el significat de l'alternança depèn del seu entorn seqüencial. L’entorn no és un conjunt de normes preestablertes que restringeixen lactivitat lingüística, sinó que és un fenomen interactiu en què els participants, a través de la interacció, produeixen nous marcs per a les activitats següents. En altres paraules, cal interpretar les alternances d'acord amb els torns precedents i posteriors i no com una llista de funcions fixades prèviament. Gumperz també admet que cal tenir en compte el context per entendre l'alternança. En aquest sentit, l'autor parla dels apunts de contextualització com a elements que

\begin{abstract}
permeten als parlants assenyalar i als oients interpretar en quina activitat es troben, com s'ha d'interpretar el contingut semàntic i com cada frase ha de ser relacionada amb la que la precedeix o la segueix. [...] Aquests elements [...] s'han d'estudiar en el seu context i no pas en abstracte. (Gumperz, 1982: 131)
\end{abstract}

Aportacions més recents, com les de Li Wei (1998; vegeu també 2002), aprofundeixen en el camí traçat prèviament per Auer. Segons aquest autor, quan s'analitza l'alternança des de la perspectiva conversacionalista cal tenir presents tres punts: el primer és la pertinença. Les interpretacions d'una interacció amb alternances de codi poden ser múltiples, això obliga l'investigador a demostrar que la seva anàlisi és pertinent a les intencions dels participants. El segon, la conseqüencialitat procedimental, implica explicar si i com el context extralingüístic té conseqüències en la interacció. És a dir, l'analista no pot dir simplement que la conversa té un caràcter «alegre»; ha de posar de manifest quin element de la interacció aporta aquest caràcter de jovialitat. Finalment, a través de l'equilibri entre l'estructura social i l'estructura conversacional es tracta de demostrar com s'expressen, s'entenen, s'accepten o es rebutgen les identitats, les actituds o les relacions i com es canvien en el transcurs d'una interacció.

Un cop hem esbossat diferents nocions relatives a les alternances de codi, tot seguit presentem diverses alternances produïdes per infants de tres a quatre anys. Lluny de presentar-les com una manca de competència lingüística, a través de l'anàlisi intentem demostrar que, fins i tot en una edat tan primerenca, les alternances han de 
ser interpretades com un recurs que empren els infants per vehicular significat social al canvi de llengua.

\section{Metodologia}

Les dades que presentarem en el proper apartat provenen de la investigació efectuada durant un any en una aula de P3 en una escola de Barcelona (vegeu, per a més detalls, Rosselló [2010a]). El grup-classe estava format per 18 alumnes: 7 de llengua inicial catalana, 3 de bilingües familiars i 8 de llengua inicial castellana. ${ }^{2}$

Per tal de tenir accés a la parla semiespontània dels infants, l'investigador, a més d'adoptar el rol d'ajudant de la mestra, també va crear racons de joc en grups de tres infants quan la resta del grup-classe anava al pati. Les úniques limitacions que hi havia per a la formació dels grups va ser el nombre d'infants i la seva llengua primera. Respecte de la formació dels grups, les primeres gravacions es van dur a terme amb quatre infants però de seguida es va desestimar aquesta opció perquè sovint es produïen converses paral.leles que en dificultaven l'audició; amb grups de tres alumnes es van poder recollir interaccions amb bona qualitat de so. La segona restricció era el grup lingüístic dels individus, ja que com a mínim un havia de tenir una llengua inicial diferent de la dels seus companys o, en tot cas, tots tres havien de ser bilingües familiars. Aquesta limitació es va imposar a causa de l'objectiu que perseguia la recerca: la negociació de codi entre iguals i el seu resultat final.

Les dades es van recollir principalment a través d'enregistraments de vídeo. En total, el corpus s'eleva a 14 hores de gravació, corresponent a 33 sessions de racons de joc. Durant les sessions, les intervencions de l'investigador es limitaven a controlar la càmera, a proposar altres activitats si els infants s'havien avorrit de la que estaven fent i a incentivar la participació d'algun alumne en

2 Definim llengua inicial com la llengua que la persona primer va parlar, a casa, quan era petita (Torres 2003: 48). En aquest article també utilitzarem amb el mateix significat el terme llengua primera (L1). cas que hagués quedat arraconat de la dinàmica de grup. En altres paraules, durant les gravacions intentava ser un observador gairebé passiu, ja que així garantia que el seu comportament lingüístic influïa tan poc com era possible en les interaccions dels infants. Això, però, va ser complicat de mantenir en totes les gravacions, ja que moltes vegades els infants s'adreçaven a l'adult per diferents qüestions. A més de la presència de l'investigador, un segon element susceptible d'alterar d'alguna manera el comportament dels informants era la mateixa videocàmera. La presència d'aquest aparell pot resultar contraproduent en investigacions amb informants joves o adults (vegeu, per exemple, Unamuno [1997: 19]). Durant el procés de recollida de dades, però, no es va percebre cap alteració del comportament dels infants, els quals mantenien en tot moment la mateixa actitud, tant si estaven sent enregistrats com si no. Aquesta naturalitat va ser, sens dubte, un dels grans avantatges de treballar amb infants de 3 a 4 anys.

\section{Alternances de codi conversacionals en in- fants}

A continuació, descriurem quatre tipus d'alternances de codi recollides en aquesta aula de P3. La primera és l'alternança relacionada amb l'exploració de codi. Com és natural, a l'edat de 3 a 4 anys encara hi ha díades d'infants que no han establert un codi de relació sistemàtic, de manera que en els casos següents es presenten alternances que no sembla que tinguin cap altre tipus de motivació que no sigui la d'explorar el codi que s'ha d'emprar amb una persona determinada. En aquest fragment es produeixen dues converses paral-leles, la de DAX amb CRP i la d'ATL amb coD; fixem-nos en aquesta última. ATL és una alumna de llengua inicial catalana que parla bàsicament en català amb tothom, amb independència de quina sigui la llengua dels seus companys; COD, en canvi, és d'L1 castellana però una part significativa dels seus enunciats són en català $(23 \%)$. 


\begin{tabular}{|c|c|c|c|c|}
\hline 1 & COD & ATL & DAX & la pe_es míal \\
\hline 2 & ATL & COD & & (... 1.67) la coD no té la pe: $\backslash$ \\
\hline 3 & & & & $\begin{array}{l}\text { (DAX ensenya com li queden } \\
\text { enganxades unes lletres) }\end{array}$ \\
\hline 4 & DAX & CRP & & mira_s'en[ganxal] \\
\hline 5 & COD & ATL & & [no tengo] ésa_tengo és:tal \\
\hline 6 & $\mathrm{DAX}$ & CRP & & $\begin{array}{l}\text { s'ha enganxat aquí_a la } \\
\text { meva [mà }]\end{array}$ \\
\hline 7 & ATL & COD & & [quina \] \\
\hline 8 & COD & ATL & & (... 0.46) ésta $\backslash$ \\
\hline 9 & ATL & COD & & $\begin{array}{l}(\ldots \text {... 1.67) sí_ però la pe no } \\
\text { la tens } \backslash\end{array}$ \\
\hline 10 & COD & ATL & & i a- i aquestal \\
\hline 11 & ATL & COD & & $\begin{array}{l}(\ldots 2.50) \text { no_ésa no } \backslash \text { ésta no } \\
\text { la tens } \backslash\end{array}$ \\
\hline
\end{tabular}

Els tres nens juguen amb unes lletres, les intenten identificar i disposar-les de manera que puguin veure-hi el seu nom. En el primer torn, COD comenta que la lletra $p$ forma part del seu nom però ATL, just en el torn posterior, l'esmena. Instants després - torn 5-, COD accepta l'error que ha comès ("no tengo ésa") i agafa una altra lletra que sí forma part del nom ("tengo ésta"). ATL li demana que li ensenyi quina lletra és (torn 7), cod l'hi mostra (torn 8) i en el 9 ATL li dóna la raó alhora que li recorda de nou que la $p$ no en forma part. Com podem observar, l'estructura seqüencial lingüística d'aquest exemple es caracteritza, fins ara, per l'ús d'una llengua diferent segons cada interlocutor. Això no obstant, aquest esquema es trenca en els torns 10 i 11 perquè es produeix un doble procés de convergència: primer de COD, que opta per alternar al català, i després, i més sorprenentment, d'ATL, que es passa al castellà malgrat el torn previ.

Una segona tipologia d'alternances té a veure amb l'estratègia per assolir un objectiu concret. BLA és una alumna bilingüe familiar que, de manera general, s'adreça a mig — d'L1 castellanaen català i castellà en proporcions molt similars. Què motiva en el següent exemple el canvi de codi de BLA?

\begin{tabular}{|l|l|l|l|}
\hline 1 & BLA & MIG & jo vull fer aquest $\backslash$ \\
\hline 2 & MIG & BLA & $(\ldots 0.65)$ no:: $\backslash$ \\
\hline 3 & BLA & MIG & yo quiero: \\
\hline 4 & MIG & BLA & que no $\backslash$ primero acaba $\mathrm{xxx} \backslash$ \\
\hline 5 & BLA & MIG & $(\ldots 0.92)$ yo- yo no $\{(\mathrm{F})$ sabo $\backslash\}$ \\
\hline 6 & MIG & BLA & $(\ldots 3.25)$ si no acabas_no $\backslash$ \\
\hline 7 & BLA & MIG & $\begin{array}{l}(\ldots 2.78) \text { y qué: } \backslash \text { yo ya he aca- yo no } \\
\text { sabo: } \backslash\end{array}$ \\
\hline
\end{tabular}

BLA i MIG juguen cada una amb un puzle. En un moment determinat, MIG acaba de fer el seu i BLA li diu, en català, que ara el vol fer ella però MIG s'hi nega en el torn $2 \mathrm{amb}$ un ambigu - des d'un punt de vista d'adscripció lingüística- "no". Davant d'aquesta situació, BLA podria haver optat per mantenir la interacció en català - de fet, no hi ha cap apunt contextualitzador que inciti al canvi de llengua-, però finalment decideix alternar cap al castellà, probablement com a estratègia aproximativa cap a MIG. Val a dir que aquesta alternança de codi ve acompanyada d'altres apunts que delaten l'objectiu de BLA, com ara un to de veu més fluix que l'habitual o l'allargament de vocals que volen reforçar la idea que el puzle que està fent és massa difícil i que el que tenia MIG li serà més senzill de completar.

La tercera alternança que presentem és la relacionada amb la comunitat de pràctiques. Molt breument, una comunitat de pràctiques és un grup de persones que comparteixen l'assoliment d'un objectiu mutu (Eckert i McConnell-Ginet, 1992: 464). Lassoliment d'aquest objectiu no és immediat, sinó que es fa a través d'un període on es posen de manifest maneres de pensar, creences, valors, relacions de poder, que es resumeixen amb el nom de pràctiques. Partint d'aquesta definició, doncs, bé podem concloure que una classe és una comunitat de pràctiques, i aquestes pràctiques també es reflecteixen en les alternances de codi. Vegem el fragment següent: 


\begin{tabular}{|c|c|c|c|c|}
\hline 1 & BLA & COD & MIG & $\begin{array}{l}\{(\mathrm{F}) \text { que ha vingut el GU- que } \\
\text { ha vingut }[\mathrm{el} \mathrm{GUR} \backslash]\}\end{array}$ \\
\hline 2 & MIG & BLA & COD & [ha vingut la-] \\
\hline 3 & BLA & COD & MIG & \begin{tabular}{l}
$\{(\mathrm{F})$ que ha vingut el GUR:\} $\\
{\text { que ha vingut [el GUR: } \backslash]\}}\end{array}$ \\
\hline 4 & MIG & BLA & COD & $\begin{array}{l}\{(\mathrm{F})[\text { que ha] vingut }[\mathrm{la} \\
\mathrm{CoD} \backslash]\}\end{array}$ \\
\hline 5 & BLA & COD & MIG & $\begin{array}{l}\{(\mathrm{F}) \text { [que ha] vingut el GUR: } \backslash \\
\text { que vindrà el MAs: } \backslash\}\end{array}$ \\
\hline 6 & MIG & BLA & COD & $\begin{array}{l}(\ldots 3.25) \text { que ha vingut a-- el } \\
\text { LUP: } \backslash\end{array}$ \\
\hline 7 & MIG & BLA & & $\begin{array}{l}\text { (... 1.11) x es que los que } \\
\text { están:__mira_está aquí } \backslash\end{array}$ \\
\hline
\end{tabular}
\end{tabular}

Els torns de l'1 al 6 contenen diferents apunts contextualitzadors que remeten a una pràctica diària que els infants duen a terme durant la primera hora de classe. Les protagonistes són, de nou, BLA i MIG. Pujades en una cadira, amb una entonació més aviat forta, repassen els noms dels seus companys sempre a partir de la mateixa fórmula i amb una mateixa entonació: "Que ha vingut...?" Aquesta activitat, quan es realitza amb tot el grup-classe, exigeix que després de cada pregunta el destinatari respongui amb un "bon dia”, però en el moment d'efectuar aquesta gravació la classe està buida, de manera que els torns se succeeixen de manera ininterrompuda. Aquestes alumnes reprodueixen una pràctica que es fa en l'àmbit de l'aula, és a dir, sota la supervisió de la mestra i en català. En conseqüència, com que és una representació de la realitat, les nenes empren el codi que és propi del ritual. En el torn 7, però, tot canvia, tant els destinataris - d'hipotèticament tota la classe a una sola persona- com la intensitat de la veu, com la temàtica — ara ja no es passa llista, sinó que s'introdueix una explicació al que s'està fent-. Aquest torn, doncs, es converteix en el punt de transició idoni per a mig per alternar del català al castellà.

La darrera de les alternances té a veure amb l'adquisició de les normes sociopragmàtiques, és a dir, les que regulen l'aparició de les llengües en un context com el de Catalunya. Abans d'explicar l'exemple següent, cal dir que demostrar una alternança d’aquesta naturalesa és difícil, com a mínim per dos motius. El primer, perquè l'edat dels informants impedeix demanar-los que fa- cin cap tipus de reflexió metalingüística sobre el seu comportament i, el segon, perquè els infants estan en ple procés d'adquisició tant de la seva L1 com de la seva L2, de manera que no es pot bandejar categòricament que el fragment no es pugui vincular - ni que sigui parcialment - a un cas d'alternança a causa de la competència lingüística. ${ }^{3}$ Per tant, seguint el model d'Auer i Li Wei que esmentàvem en el primer apartat d'aquest article, intentarem aportar dades que avalin la justificació de la interpretació.

Els dos infants que intervenen en aquest fragment són GUR i MIG. El primer és fill d'un matrimoni que parla entre si en castellà tot i que els dos progenitors se li adrecen en català, cosa que ens permet categoritzar l'infant com de llengua inicial catalana. Durant el transcurs de la recerca es va poder comprovar que GUR era, de tots els alumnes d'L1 catalana, el que menys torns parlava en català $(62 \%)$ i alhora el que més emprava el castellà $(16,5 \%)$. Per la seva banda, com ja hem vist, MIG és d'L1 castellana amb una producció de torns de parla catalana al voltant del $25 \%$, mentre que els seus torns en castellà ascendeixen a $46 \%$.

\begin{tabular}{|c|c|c|c|}
\hline 1 & GUR & MIG & $\begin{array}{l}\text { està tancada la botiga } \backslash(\ldots 0.92) \\
\text { està tancada la botiga_mama }\end{array}$ \\
\hline 2 & MIG & GUR & $(\ldots 0.83)$ què $\mid$ \\
\hline 3 & GUR & MIG & està tancada la botigal \\
\hline 4 & MIG & GUR & $(\ldots 0.46)$ què \\
\hline 5 & GUR & MIG & està $\{(\mathrm{F})$ tancada $\}$ la botiga $\backslash$ \\
\hline 6 & MIG & GUR & quèl \\
\hline 7 & GUR & MIG & està tancada la botigal \\
\hline 8 & & & (se sent JAE de fons) \\
\hline 9 & MIG & GUR & $\begin{array}{l}\text { (... 1.85) quiero leche que no } \\
\text { tengo más } \backslash \text { yo voy a traer }[\mathrm{xxx} \backslash]\end{array}$ \\
\hline 10 & GUR & MIG & $\begin{array}{l}\text { [quiero] más café } \backslash \text { ha co- ha } \\
\text { començat/ }\end{array}$ \\
\hline 11 & MIG & GUR & $(\ldots 0.37) \mathrm{nol}$ \\
\hline
\end{tabular}

$3 \mathrm{Si}$ voleu veure exemples d'alternances vinculades a la manca de competència lingüística en aquests mateixos infants, podeu consultar Rosselló (2010b). 
El context en què es produeix aquest episodi s'emmarca en la reproducció dels rols familiars: MIG fa de mare i GUR de fill que torna de comprar però que s'ha trobat la botiga tancada. Precisament aquest fet és el que transmet GUR en la seva primera intervenció, que en no obtenir resposta, al cap d'un segon insisteix en el missatge, aquest cop tancant el torn amb el vocatiu "mama". Gairebé un segon més tard - torn 2-, MIG pregunta "què?", en el sentit de demanar un aclariment davant d'un missatge que no ha entès, interpretació que, si presenta qualsevol ombra de dubte, queda esvaïda pel nombre de vegades que la mateixa pregunta és repetida en els torns posteriors.

Com bé sabem, un comportament força estès en la nostra comunitat lingüística, especialment quan l'emissor s'adreça en català, és el canvi de llengua al primer indici que l'interlocutor no hagi entès el nostre missatge. Doncs bé, en els dos primers torns del fragment que analitzem, ja apareixen prou apunts contextualitzadors perquè GUR canviï de llengua si seguís les normes d'interacció que imperen sobre bona part de la població catalanoparlant: el silenci de 0,92 segons després del primer enunciat, el fet que li hagi de formular de nou una segona vegada o la mateixa pregunta de MIG. Aquests apunts són motius suficients per alternar cap al castellà en les negociacions de codi locals. Això no obstant, GUR, en el torn 3, no modifica en absolut la seva formulació: ni canvia de llengua, ni busca una expressió alternativa que faciliti la comprensió a MIG. Per què no ho fa? Amb les dades de què disposem, no podem al-legar de manera definitiva que no sigui perquè encara no ha adquirit prou cabal lèxic en la seva L2. Això no obstant, i atesos els factors sociolingüístics familiars i d'ús de les llengües amb els seus companys que hem esmentat anteriorment, ens inclinem a pensar que l'origen d'aquest cas de divergència lingüística és la no-adquisició de les normes sociopragmàtiques que regulen l'aparició del català i del castellà.

Tornant a l'exemple que estàvem descrivint, l'estructura dialògica es manté fins al torn 9 , moment en què MIG - després de preguntar tres vegades “què?", de diverses pauses i de no sortir de l'entrellat- decideix emprendre, en castellà, la interacció cap a una nova temàtica en què ella té la iniciativa. GUR, en el torn 10, segueix la línia que proposa MIG, atès que abandona la idea de la botiga, i ho fa amb una alternança interoracional que acaba amb una pregunta en català que mig respon.

\section{Conclusió}

En aquest article hem presentat el significat que poden tenir les alternances de codi en un grup d'infants de P3. Lluny de presentar-les com un dèficit lingüístic, les alternances són un recurs de què disposa el parlant per aportar significat social al canvi de llengua. Això no implica que no hi hagi alternances causades per una manca de competència lingüística però, fins i tot a una edat tan primerenca com els 3 o 4 anys, és clarament un error adscriure-les totes a una mancança en l'adquisició del codi. En aquest sentit, les alternances que hem analitzat remeten a diferents processos, des de l'exploració de codi per determinar una llengua d'interacció estable en una díada fins a una alternança vinculada amb la comunitat de pràctiques, en què la reproducció de rituals que es fan en l'àmbit públic de l'aula després es veu reflectida en el comportament lingüístic dels infants en les activitats no tutoritzades.

El fet que les alternances vehiculin significat social comporta que algunes que són pròpies de la infantesa tendeixin a desaparèixer a mesura que la persona creix i que n'incorpori de noves. Una de les anàlisis més exhaustives pel que fa a les funcions de les alternances en escolars catalans d'11 a 12 anys és l'estudi de Galindo (2008; vegeu també 2006). Lautora identifica les sis alternances que tenen una recurrència més alta: canvi de llengua en funció de l'interlocutor; per expressar una segona veu; per manca de competència lingüística; per incorporar expressivitat; per insistir o remarcar, i per aconseguir efectes lúdics o humorístics. Algunes d'aquestes alternances també apareixen en el nostre corpus; d'altres no. En aquest sentit, hem apuntat que l'alternança relacionada amb la no-adquisició - encara- de les normes sociopragmàtiques que regulen l'aparició del castellà i del català provoca que aquesta darrera llengua tingui una presència molt més elevada en interaccions entre membres de grups 
lingüístics diferents que no pas tindria si els interlocutors fossin d'edats més avançades.

\section{Bibliografia}

Auer, P. (1995). "The pragmatics of codeswitching: a sequential approach", a: L. Milroy; P. Muysken (ed.), p. 115-135.

BoIx, E. (1993). Triar no és trair. Identitat i llengua en els joves de Barcelona. Barcelona: Edicions 62.

Eckert, P.; MCConnell-Ginet, S. (1992). "Think practically and look locally: Language and gender as community-based practice". Annual Review of Anthropology, 21: 461-490.

Galindo, M. (2006). «Les llengües a l'hora del pati. Usos lingüístics en les converses dels infants de primària a Catalunya», tesi doctoral llegida a la Universitat de Barcelona.

- (2008). Les llengües en joc, el joc entre llengües. Lleida: Pagès Editors.

Gumperz, J. J. (1982). Discourse strategies. Cambridge: Cambridge University Press.

Gumperz, J. J. (ed.) (1982). Language and social identity. Cambridge: Cambridge University Press.

Köppe, R.; Meisel, J. (1995). "Code-switching in bilingual first Language acquistion”, a: L. Milroy; P. Muysken (ed.), p. 276-301.

LI WeI (1998). “The «why» and «how» questions in the analysis of conversational codeswitching", a: P. Auer (ed.), p. 156-176.

- (2002). "«What do you want me to say?» On the conversation analysis approach to bilingual interaction". Language in Society 31: pàg. 159-180.

Milroy, L.; Mursken, P. (ed.) (1995). One speaker, two languages. Cross-disciplinary perspectives on code-switching. Cambridge: Cambridge University Press.

Myers-Scotton, C. (1993). Social motivation for codeswitching. Evidence from Africa. Oxford: Clarendon Press-Oxford.

Poplack, S. ([1980] 2000). “Sometimes I'll start a sentence in Spanish y termino en español: toward a typology of code-switching", a: Li WeI (ed.), p. 221-256.

Rosselló, C. de (2010a). Aprendre a triar. Ladquisició de les normes d'ús i alternança de codis en l'educació infantil. Universitat de Barcelona.

— (2010b). “En quina llengua ens parlarem?». Negociacions de codi en una aula de P3". Revista de Llengua i Dret, 54: 277-295.

Torres, J. (2003). "Lús oral familiar a Catalunya”. Treballs de Sociolingüística Catalana, 17: $47-76$.

Unamuno, V. (1997). "Lenguas, identidades y escuela: etnografía de la acción comunicativa". Tesi doctoral llegida a la Universitat de Barcelona.

VILA, F. X. (1996). "When classes are over. Language choice and language contact in bilingual education in Catalonia". Tesi doctoral llegida a la Vrije Universiteit Brussel.

WeINREICH, U. ([1953] 1996). Languages in contact. Findings and problems. The Hague-París: Mouton. 